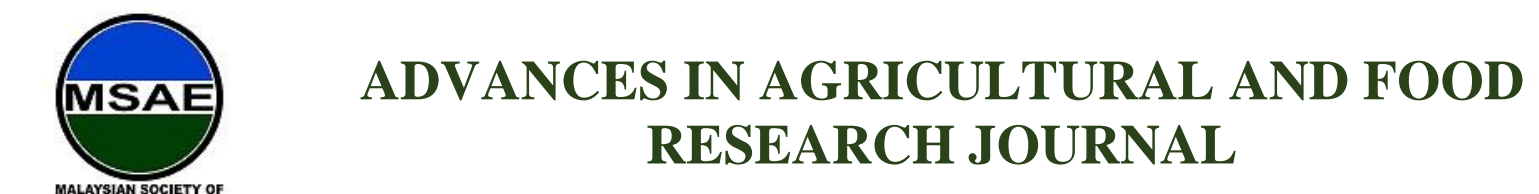

HH PUBLISHER

Original Research Article

\title{
Effect of Heat Treatment on Rheological Properties of Bambangan (Mangifera Pajang Kosterm) Fruit Juice
}

\author{
Jumardi Roslan ${ }^{1 *}$, Hay Chye Ling ${ }^{1}$, Mohd Dona Sintang ${ }^{1}$, Suryani Saallah ${ }^{2}$ \\ ${ }^{1}$ Faculty of Food Science and Nutrition, Universiti Malaysia Sabah, Jalan UMS, 88400 Kota Kinabalu, Sabah, \\ jumardi@ums.edu.my, haychyeling@gmail.com,donasintang@ums.edu.my \\ ${ }^{2}$ Bioetchnology Research Institute, Universiti Malaysia Sabah, Jalan UMS, 88400 Kota Kinabalu, Sabah, \\ suryani@ums.edu.my \\ *Corresponding author: Jumardi Roslan, Faculty of Food Science and Nutrition, Universiti Malaysia Sabah, \\ Jalan UMS, 88400 Kota Kinabalu, Sabah, jumardi@ums.edu.my
}

\begin{abstract}
Bambangan (Mangifera pajang Kosterm) is an indigenous fruit that can be found in Borneo Island including Sabah and Sarawak (Malaysia), Kalimantan (Indonesia), and Brunei. Besides being eaten fresh, the pulp of bambangan fruit can be processed for juice production and expand its market potential. During the fruit juice processing, application of heat treatment such as pasteurization and sterilization might influence their rheological behavior. Thus, the present study aims to investigate the effect of heat treatment on the rheological properties of bambangan fruit juice (BFJ). The freshly squeezed BFJ was subjected to different heat treatment conditions; sterilization $\left(121^{\circ} \mathrm{C}, 3\right.$ minutes $)$, mild temperature long time (MTLT) pasteurization $\left(65^{\circ} \mathrm{C}, 15\right.$ minutes), and high temperature short time (HTST) pasteurization $\left(90^{\circ} \mathrm{C}, 1\right.$ minute). Rheological analysis of the heat-treated BFJ was performed using a rheometer at a shear rate ranging from 1 to $250 \mathrm{~s}^{-1}$ and a temperature between $5^{\circ} \mathrm{C}$ to $70^{\circ} \mathrm{C}$. Pasteurization at $90{ }^{\circ} \mathrm{C}$ for 1 minute (HTST) was found to be the most suitable heat treatment for the BFJ. At this condition, the BFJ exhibited a non-Newtonian pseudoplastic fluid behavior $(n<1)$, fitted well with the Herschel-Bulkey model. The value of parameters obtained from Herschel-Bulkley equation for HTST treatment of bambangan juice were $n=0.83, k=0.32$ and yield stress $=3.96$. The viscosity values of HTST bambangan juice at the temperature of $5,20,40$ and $70{ }^{\circ} \mathrm{C}$ were $3.53,2.33,1.53$ and 1.76 Pa.s respectively. This rheological information is of fundamental importance in optimizing equipment design, process control, and sensory evaluation.
\end{abstract}

Keywords: Bambangan fruit; bambangan fruit juice; heat treatment; rheological properties

Received: $28^{\text {th }}$ August 2020

Accepted: $30^{\text {th }}$ September 2020

Available Online: $14^{\text {th }}$ October 2020

Citation: Roslan J, Ling HC, Sintang MD, et al. Effect of Heat Treatment on Rheological Properties of Bambangan (Mangifera Pajang Kosterm) Fruit Juice. Adv Agri Food Res J 2020; 1(2): a0000115. https://doi.org/10.36877/aafrj.a0000115

\section{Introduction}

Bambangan (Mangifera pajang Kosterm) is an underutilized fruit endemic to Borneo Island (Sabah and Sarawak of Malaysia, Brunei, and Kalimantan, Indonesia). It is a type of 
wild mango belongs to the Anacardiaceae family. The trees can grow up to $20 \mathrm{~m}$ in height and bears up to hundreds of semi-oval shaped fruits. The uniqueness of thee fruits are the size can reach up to three times larger than common mangos (Mangifera indica), has a thicker peel, rough-brown skin, big seed size and can weigh up to $2 \mathrm{~kg}$. The fruits consist of pulp which represents $60-65 \%$ of the total weight, kernel (15-20\% of total weight) and peel (10$15 \%$ of the total weight). The fruit pulp has a delightful mango fragrance, highly fibrous, very juicy with a unique aromatic flavor and strong smell (Mohd Fadzelly \& Jeffrey, 2013).

Several scientific studies have discovered the health-promoting benefits of bambangan fruit attributed to its rich Vitamin $\mathrm{C}$ content and superior antioxidant properties. Usually, the fruits are eaten fresh, pickled or used as an ingredient in local dishes. Production of juice from bambangan fruit is an ideal solution to expand its potential market (Mohd Fadzelly \& Jeffrey, 2013). Although, the fruit juice is highly susceptible to microbial, enzyme, chemical, and physical degradations but affect the product quality and shelf-life during cool and room temperatures storage. Various approaches have been investigated to overcome this problem, but thermal treatment such as pasteurization and sterilization remains the most cost-effective strategy to prolong the shelf-life of juice product by inhibiting microorganisms and enzymes that can cause fruit juice deterioration (Aguilo-Aguayo et al., 2009; Rawson et al., 2011; Jimenez-Sanchez et al., 2017).

During the processing of fruit juice, thermal treatment may affect the fruit juice attributes, particularly on rheological behavior (REFs). Rheology attempts to define the relationship between stress acting on given materials and the resulting shear strain developed in this material. When stress is applied to any food material like liquid food, a strain develops in the materials causing the deformation of materials as in the flow of juices through pipes or movement of semi-solid foods (Rosnah et al. 2007). Therefore, this rheological information is useful for prediction of heat and mass transfer coefficient where they can be applied in food handling and processing, quality control, sensing and for the design or development of equipment in the fruit juice industry (Rosnah et al., 2013; Sinemobong \& Emediong, 2016).

Several studies have been conducted to investigate rheological properties of fruit juice under the influence of heat treatment including grape juice (Mauricio et al., 2017), pineapple juice (Sinemobong \& Emediong, 2016), white carrot juice (Zbigniew et al., 2015), Yankee pineapple juice (Rosnah et al., 2013), mango juice (Manish et al., 2007), and strawberry juice (Juszczak \& Fortuna, 2003). Generally, fruit juices exhibited a non-Newtonian flow behavior known as shear-thinning behavior, a typical pseudoplastic fluid, which can be explained by several models such as the Newtonian, Herschel-Bulkley, Bingham, and Power Law models (Quek et al., 2013). However, to date, no rheological information is available for juice made from bambangan fruit. Therefore, the study was undertaken to investigate the rheological behavior and temperature-viscosity relationship of bambangan fruit juice under different heat treatment conditions. 


\section{Materials and Methods}

\subsection{Preparation of bambangan fruit juice (BFJ)}

Bambangan fruits (Mangifera pajang) were bought from Ranau market, Sabah and brought to the laboratory. Upon arrival at laboratory, the fruits were washed, and the peel was manually removed to get the pulp. The pulp maturity was evaluated according to the total soluble solid ( ${ }^{\circ}$ Brix) using refractometer (Atago, Germany) with the matured bambangan fruit was considered approximately around $15^{\circ}$ Brix of total soluble solid. The pulp was then cut into smaller pieces followed by blending using a food processor (Dito Sama, Italy) and filtered to get the juice. The juice was prepared with a ratio of 1:1 (water and flesh) and then placed in $500 \mathrm{~mL}$ Schott bottle.

\subsection{Heat treatments of $B F J$}

The bambangan fruit juice $(\mathrm{BFJ})$ was then treated at three different heat treatment conditions denoted as high temperature short time (HTST) for pasteurization at $90^{\circ} \mathrm{C} / 1$ minute, mild temperature long time (MTLT) for pasteurization at $65^{\circ} \mathrm{C} / 15$ minutes (Pareek et al., 2011; Wang et al., 2018) and sterilization at $121^{\circ} \mathrm{C} / 3$ minutes using horizontal retort (CY-3000H, China) (Chen et al., 2015). BFJ without treatment were used as control. All samples were stored in a cold room at the temperature of $-20^{\circ} \mathrm{C}$ until further use.

\subsection{Rheological characterizations}

Rheometer (TA Instruments AR1500EX, USA) with computer software (Rheology Advantage Data Analysis Program, TA, New Castle, DE) was used to determine the rheological properties of BFJ. Measurement of the rheological properties was carried out using cone and plate system. Calibration steps were carried out before operating the rheometer. Cone-plate geometry with a diameter of $60 \mathrm{~mm}$ and an angle of $2^{\circ}$ was used. A total of $3.5 \mathrm{~mL}$ sample from each of the treatments was tested at a shear rate within the range of $1-250 \mathrm{~s}^{-1}$ (Mauricio et al. 2017). Sample temperature was controlled and regulated at $5^{\circ} \mathrm{C}$, a common storage temperature for fruit juice. The rheological models were fitted to the experimental shear stress and shear rate data according to the rheological models as follow: Newtonian, Bingham, Casson, Power Law, and Herschel-Bulkley. The best rheological model that fitted the experimental data was selected according to the lowest relative error (Equation 1) between observed and predicted values.

$$
\text { Relative error }(\%)=[(\text { Observed value }- \text { predicted value }) / \text { Observed value }] \text { x } 100
$$

After that, rheological data obtained was fitted into pseudoplastic fluid (HerschelBulkley) model (Equation 2) in which $\tau$ is shear stress $(\mathrm{Pa}), \gamma$ is shear rate $\left(\mathrm{s}^{-1}\right), \tau_{0}$ is yield stress $(\mathrm{Pa}), K$ is consistency coefficient $\left(\mathrm{Pa}^{1 / 2} \mathrm{~s}^{\mathrm{n}}\right)$, and $n$ is flow behaviour index. 
Herschel-Bulkley, $\tau=\tau_{0}+K(\gamma)^{\mathrm{n}}$

Different $n$ value indicates the fluid behavior. For Newtonian behavior, $n=1$ while $n$ $<1$ indicate pseudoplastic behavior and $n>1$ for dilatant behavior. Viscosity measurement was further carried out using Peltier control system with temperature ramp from 5 to $70^{\circ} \mathrm{C}$. Perimeter of the exposed sample was covered with metal solvent trap to minimize evaporation of sample at a higher temperature. Experiments were performed in triplicate.

\subsection{Statistical Analysis}

Statistical Package for the Social Science (SPSS) version 25 was used for statistical analysis. Mean and standard deviation was calculated for triplicate and one-way analysis of variance (ANOVA) followed by Tukey's B test was used to evaluate the differences among treatment at significant level of $5 \%(p<0.05)$.

\section{Results and Discussions}

\subsection{Selection of Rheological Model}

Bambangan fruit juice (BFJ) was subjected to three different heat treatment conditions; medium temperature-long time (MTLT), high temperature-short time (HTST), sterilization and no heat treatment as control. All the treated BFJ samples were tested using the existing rheological models including Newtonian, Bingham, Casson, Power Law and Herschel-Bulkley. The best fitted model was chosen depending on the lowest relative error. Based on the results presented in Table 1, the lowest relative error was obtained by the Herschel-Bulkley model, indicating that this model was the best to describe the rheological behavior of the treated BFJ.

Table 1. Relative error values of heat treated BFJ at different rheological model

\begin{tabular}{lccccc}
\hline & \multicolumn{5}{c}{ Relative error (\%) } \\
\cline { 2 - 5 } Treatment/Model & Newtonian & Bingham & Casson & Power Law & Herschel-Bulkley \\
No heat treatment & 283.0 & 28.0 & 13.9 & 60.8 & 9.3 \\
MTLT & 267.9 & 76.0 & 37.5 & 21.6 & 9.8 \\
HTST & 287.0 & 73.5 & 35.2 & 23.7 & 9.2 \\
Sterilization & 282.3 & 79.7 & 40.8 & 16.6 & 6.9 \\
\hline
\end{tabular}

\subsection{Analysis and modelling of fluid flow behavior using Herschel-Bulkley}

All the treated BFJ were further analyzed for their fluid flow behavior using HerschelBulkley model. The plot of shear stress and at shear rate ranging from 1-250 s $\mathrm{s}^{-1}$ for the BFJ is as shown in Figure 1. All samples exhibited a non-Newtonian behavior with a concave downward curve pattern, describing a pseudoplastic behavior. In addition, the flow curves 
demonstrate a static yield stress, indicating the bambangan pulp structure is sensitive and easily disrupted by fluid movement (Adriano \& Sundaram, 2009).

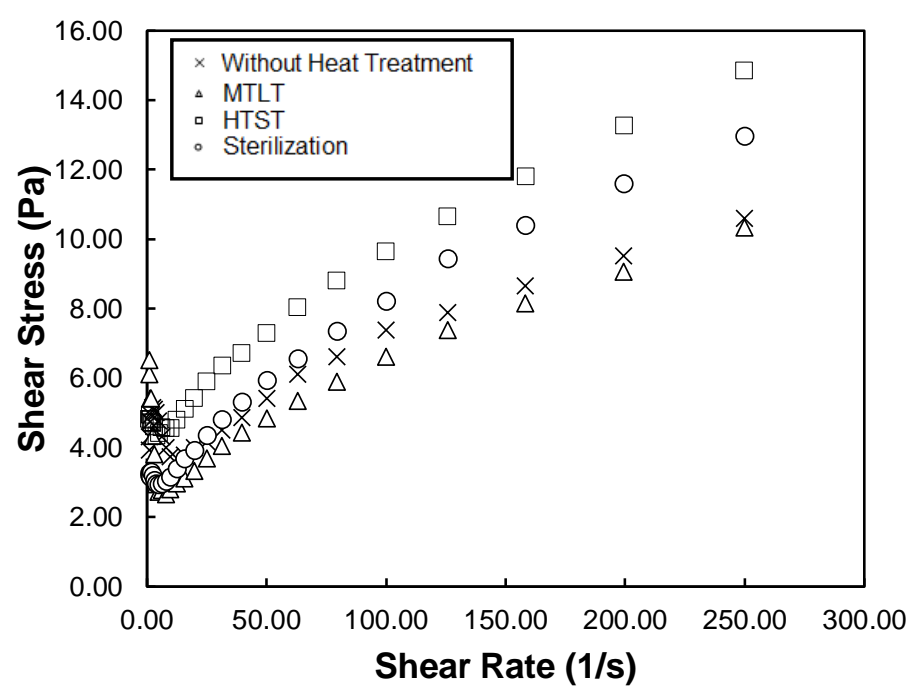

Figure. Flow curves of bambangan juice with different heat treatments

A decreasing in shear stress at the beginning and increases as the shear rate increased is an indication of initial yield stress. This phenomenon occurs due to the presence of entangled pulp that prevents the free flow of the juices at zero shear rates. Therefore, the cross-linking structure needs to be disrupted using appropriate shear rates and temperatures before the flow can occur. A similar pattern was also reported by Rosnah et al., (2013) for pineapple juice. BFJ treated using HTST condition has the highest shear stress (4.95-14.86 $\mathrm{Pa})$, followed by sterilization (3.30-12.98 Pa), without heat treatment (4.99-10.59 Pa) and MTLT (6.51-10.33 Pa). A high shear stress value for HTST might be due to the low viscosity of the juice as a result of the heat treatment. This is an agreement with the findings by Hassan and Hobani (1998) where the shear stress is enhanced with the increase in temperature. This might be due to the rearrangement of the particles in parallel directions and their breaking into smaller particles. These particles can flow more easily due to the decrease in the particleparticle interactions, thus reducing the viscosity. This finding demonstrates the notable effect of heat treatments on the flow behavior of the BFJ.

The Herschel-Bulkley model was used to calculate rheological parameters including flow behavior index $(n)$, consistency coefficient $(K)$ and yield stress $\left(\sigma_{0}\right)$ (Table 2$)$. As expected, the increase in temperature reduces the flow behavior index $(n)$ for all the treatments but have different consistency coefficient $(K)$ and yield stress $\left(\sigma_{0}\right)$. The highest $\mathrm{n}$ value was obtained for BFJ without treatment (1.11) which close to the Newtonian index value of $n=1$. The heat-treated BFJ has flow behavior index of less than 1 with values of 0.85, 0.83, 0.77 for MTLT, HTST and sterilization, respectively. This is a clear indication that heat treatment caused the BFJ to show pseudoplastic behavior and deviate from the 
Newtonian fluid. However, there was no significant difference $(p>0.05)$ between the $\mathrm{n}$ values of all treatments. A high flow behavior index value in the untreated BFJ was probably due to the presence of a significant amount of water where the BFJ was made up of a 1:1 ratio between puree and water. Heat treatment may cause changes in the viscosity as a result of water removal, leading to a decrease in $n$ values. The $n$ value of less than 1 obtained here for the heat-treated BFJ is consistent with the previous finding reported by Manish et al. (2007), Chin et al. (2009) and Quek et al. (2013) on mango, pomelo and soursop juices, respectively.

As for consistency coefficient $(K)$, the values were varying with different heat treatment used. The highest $K$ value was obtained when BFJ was treated using HTST $(0.32)$ followed by sterilization (0.20), MTLT (0.14) and without heat treatment (0.07), respectively. There was a significant difference $(p<0.05)$ for the $K$ value between untreated and HTST but no significant difference for MTLT and sterilization. The variation in consistency coefficient of BFJ might be due to the presence of water which affected by the different temperature and heating time. The values of consistency coefficient are very important in juice processing especially during pasteurization where the increase in consistency coefficient will cause the flowing rate in the pipe to decrease due to more flow resistance (Quek et al. 2013).

Table 2. Experimental data fitted to parameters of Herschel-Bulkley model for heat-treated BFJ

\begin{tabular}{lccc}
\hline Treatment & $\boldsymbol{n}$ & $\boldsymbol{K}$ & Yield Stress, $\boldsymbol{\sigma}_{\mathbf{0}}$ \\
\hline No heat treatment & $1.11 \pm 0.34^{\mathrm{a}}$ & $0.07 \pm 0.04^{\mathrm{b}}$ & $4.18 \pm 0.79^{\mathrm{a}}$ \\
MTLT & $0.85 \pm 0.10^{\mathrm{a}}$ & $0.14 \pm 0.02^{\mathrm{ab}}$ & $2.54 \pm 0.20^{\mathrm{a}}$ \\
HTST & $0.83 \pm 0.36^{\mathrm{a}}$ & $0.32 \pm 0.14^{\mathrm{a}}$ & $3.96 \pm 1.55^{\mathrm{a}}$ \\
Sterilization & $0.77 \pm 0.04^{\mathrm{a}}$ & $0.20 \pm 0.08^{\mathrm{ab}}$ & $2.64 \pm 1.42^{\mathrm{a}}$ \\
\hline
\end{tabular}

*Data presented in mean \pm standard deviation $(n=3)$. Values followed by different superscript within each column indicate significant difference $(p<0.05)$.

The untreated BFJ has the highest yield stress (4.18) followed by the HTST (3.96), sterilization (2.64) and MTLT (2.53). However, there was no significant difference $(p>0.05)$ between the yield stress values of all treatments. The yield stress gives information on the stress that must be applied to the sample before it starts to flow. A high yield stress in untreated BFJ indicates that a higher force requires to flow the juice.

\subsection{Effect of Temperature on The Viscosity of The Untreated and Treated BFJ}

The untreated and heat-treated BFJ were further analyzed for their viscosity at temperature ramp from 5 to $70{ }^{\circ} \mathrm{C}$ (Table 3) to elucidate their temperature-viscosity relationship. A high viscosity was found for the untreated BFJ and thevalue ranging from 4.81 to 2.32 Pa.s, followed by HTST (3.53-1.76 Pa.s), sterilization (2.76-0.97 Pa.s) and MTLT (2.04-0.98 Pa.s). Untreated BFJ would remain viscous due to the presence of suspended compound like pulp fiber (hemicellulose and cellulose), protein, pectin and pectin 
methyl esterase in the juice. These colloidal suspensions cause the viscous, cloud and turbidity appearance in the juice (Sara \& Aman, 2018). As compared to other samples (HTST, MTLT and sterilization), heat treatment was applied first during pasteurization and sterilization causing its viscosity to change due to treatment at different temperatures. The study of the effect of temperature on viscosity can be considered as a second heat treatment on the sample which has resulted in more structure would be breakdown and subsequently reduces the viscosity. When subjected to heat treatment, it could breakdown the colloidal suspensions (Tanaka \& Hoshino, 2003) and reduces the juice viscosity, thus reducing the yield stress. Only slight reduction in yield stress is observed for the HTST indicates a lower reduction in viscosity as well as pulp fiber disruption as the heat treatment was carried out at a relatively short time (1 minute). As opposed to that, the BFJ treated under MTLT condition shows the lowest yield stress, high probably due to the longer heat treatment duration (15 minutes). At this condition, the system has sufficient time to break down the bambangan pulp fiber which resulted in a low viscosity as well as yield stress.

Table 3. Viscosity values of heat treated bambangan fruit juice at different temperature

\begin{tabular}{lcccc}
\hline & \multicolumn{4}{c}{ Viscosity (Pa. s) of bambangan juice versus temperature } \\
\hline Treatment & $\mathbf{5 . 5}^{\circ} \mathbf{C}$ & $\mathbf{2 0 . 0}^{\circ} \mathbf{C}$ & $\mathbf{4 0 . 0}^{\circ} \mathbf{C}$ & $\mathbf{7 0 . 0}^{\circ} \mathbf{C}$ \\
No heat treatment & $4.81^{\mathrm{a}} \pm 1.35$ & $3.01^{\mathrm{a}} \pm 0.70$ & $2.13^{\mathrm{a}} \pm 0.16$ & $2.32^{\mathrm{ab}} \pm 0.61$ \\
MTLT & $2.04^{\mathrm{a}} \pm 0.36$ & $1.39^{\mathrm{a}} \pm 0.20$ & $1.33^{\mathrm{a}} \pm 0.06$ & $0.98^{\mathrm{b}} \pm 0.05$ \\
HTST & $3.53^{\mathrm{a}} \pm 0.39$ & $2.33^{\mathrm{a}} \pm 0.09$ & $1.53^{\mathrm{a}} \pm 0.03$ & $1.76^{\mathrm{a}} \pm 0.10$ \\
Sterilization & $2.76^{\mathrm{a}} \pm 1.97$ & $1.69^{\mathrm{a}} \pm 2.27$ & $1.01^{\mathrm{a}} \pm 0.91$ & $0.97^{\mathrm{b}} \pm 0.75$ \\
\hline
\end{tabular}

*Data presented in mean \pm standard deviation $(n=3)$. Values followed by different superscript within each column indicate significant difference $(p<0.05)$.

It should be noted that the heat treatment applied for the BFJ in the previous section resulted in high viscosity due to water removal. As for the heat-treated BFJ (HTST, MTLT and sterilization), when the samples were subjected to heating at temperature ramp from 5 to $70{ }^{\circ} \mathrm{C}$, the reduction of viscosity occurred due to the breakdown of bambangan pulp fibre. These results clearly supported the values obtained from the flow behavior analysis (Figure 1) and analysis of fitted parameters on Herschel-Bulkley model (Table 2). It is also in agreement with the findings reported by Wijitra et al. (2013) where viscosities of fruit juices were varies at different temperature depending on the type of fruit juice used. Lower viscosity value for BFJ treated using MTLT might also be attributed to the hydrolysis reaction by the action of enzymes present in the juice (Solange et al. 2009). Changes in viscosity of fruit juice may have a big impact on the process especially those that involve mixing (stirrer dimension, type and pump capacity, reactor liquid circulation, etc).

\section{Conclusion}

The effect of pasteurization (MTLT and HTST) and sterilization of bambangan fruit juice $(\mathrm{BFJ})$ on the rheological behavior is satisfactorily be described by Herschel-Bulkley 
model that showed a pseudoplastic fluid behavior. The findings that obtained from this study provide useful information for juice manufacturers to design a suitable equipment and transport systems in juice processing.

Author Contributions: Conceptualization, J.R., M.D.S. and S.S.; funding acquisition, J.R.; investigation, H.C.L.; writing —original draft preparation, H.C.L., J.R. and S.S..; writing—review and editing, J.R.D, S.S. and M.D.S

Funding: This work was funded by the Universiti Malaysia Sabah through Acculturation Grant Scheme with grant number SGA0019-2019.

Conflicts of Interest: The authors declare no conflict of interest.

\section{References}

Adriano, S. \& Sundaram, G. (2009). Yield stress in foods: Measurements and applications. International Journal of Food Properties, 12(1), 70-101.

Aguilo-Aguayo, I., Oms-Oliu, G., Soliva-Fortuny, R., et al. (2009). Changes in quality attributes throughout storage of strawberry juice processed by high intensity pulsed electric fields or heat treatments. Food Science and Technology, 42, 813-818.

Chen, X., Qin, W., Ma, L., et al. (2015). Effect of high-pressure processing and thermal treatment on physicochemical parameters, antioxidant activity and volatile compounds of green asparagus juice. $L W T$ - Food Science and Technology, 62, 927-33.

Chin, N.L., Chan, S.M., Yusof, Y.A., et al. (2009). Modelling of rheological behaviour of pummelo juice concentrates using master-curve. Journal of Food Engineering, 93(2), 134-140.

Hassan, B.H \& Hobani, A.I. (1998). Flow properties of rossele (Hibiscus sabdariffa L.) extract. Journal of Food Engineering, 35(4), 459-470.

Jimenez-Sanchez, C., Lozano-Sanchez, J., Segura-Carretero, A., Fernandez-Gutierrez, A. (2017). Alternatives to conventional thermal treatments in fruit-juice processing. Part 1: Techniques and applications. Critical Reviews in Food Science and Nutrition, 57, 501-23.

Juszczak, L. \& Fortuna, T. (2003). Viscosity of concentrated strawberry juice: Effect of temperature and soluble solids content. Electronic Journal of Polish Agricultural Universities. Food Science and Technology, 6(2).

Manish, D., Verma, R.C., \& Jaaffrey, S.N.A. (2007). Effect of temperature and concentration on rheological properties of "Kesar" mango juice. Journal of Food Engineering, 80, 1011-1015.

Mauricio, B.M.C., Lilian, F.L.B., Gisandro, R.C., et al. (2017). Experimental study of physical and rheological properties of grape juice using different temperatures and concentrations. Part I: Cabernet Sauvignon. Food Research International, 100, 724-730.

Mohd Fadzelly, A.B. \& Jeffrey R.F. (2013). A review on underutilized indigenous bambangan (Mangifera pajang) fruit as a potential novel source for functional food and medicine. Journal of Medicinal Plants Research, 7(45), 3292-3297. 
Pareek, S., Paliwal, R., \& Mukherjee S. (2011). Effect of juice extraction methods and processing temperaturetime on juice quality of Nagpur mandarin (Citrus reticulata Blanco) during storage. Journal of Food Science and Technology, 48, 197-203.

Quek, M.C., Chin, N.L., \& Yusof, Y.A. (2013). Modelling of rheological behaviour of soursop juice concentrates using shear rate-temperature-concentration superposition. Journal of Food Engineering, $118(4), 380-386$.

Rawson, A., Patras, A., Tiwari, B.K., et al. (2011). Effect of thermal and non-thermal processing technologies on the bioactive content of exotic fruits and their products: review of recent advances. Food Research International, 44, 1875-1887.

Rosnah S., Wan, R.W.D., Mohd. Sobri, T., et al. (2007). Physical properties of the josaphine variety of pineapple fruit. International Journal of Food Engineering, 3(5), Art 9.

Rosnah S., Chia, S.L., Noranizan, M.A., et al. (2013). Rheological properties of ultraviolet-irradiated and thermally pasteurized Yankee pineapple juice. Journal of Food Engineering, 116, 548-553.

Sara, A. \& Aman, M.Z. (2018). A review of pectin methylesterase inactivation in citrus juice during pasteurization. Trends in Food Science \& Technology, 71, 1-12.

Sinemobong, O.E. \& Emediong, U.U. (2016). Effect of temperature on the rheological properties of pineapple juice (Ananascomosus). International Journal of Latest Research in Science and Technology, 5(2), 8690.

Solange, V., Mara, G.N.Q., José, A.R.de.S., et al. (2009). Temperature effect on the rheological behaviour of carrot juice. Journal of Food Engineering, 92, 269-274.

Tanaka, A. \& Hoshino, E. (2003). Similarities between the thermal inactivation kinetics of Bacillus amyloliquefaciens $\alpha$-amylase in an aqueous solution of sodium dodecyl sulphate and the kinetics in the solution of anionic-phospholipid vesicles. Biotechnology and Applied Biochemistry, 38, 175-181.

Wang, Y., Li, W., Ma, Y., et al. (2018). Effect of thermal treatments on quality and aroma of watermelon juice. Journal of Food Quality, https://doi.org/10.1155/2018/9242675.

Wijitra, L., Nathalie, D.C., Vera, V.H., et al. (2013). Impact of thermal treatment on physicochemical, antioxidative and rheological properties of white-flesh and red-flesh dragon fruit (Hylocereus spp.) purees. Food Bioprocess Technology, 6, 416-430.

Zbigniew, K., Rafał, N., Tomasz, G., et al. (2015). Effect of pasteurization on rheological properties of white carrot juice. Agriculture and Agricultural Science Procedia, 7, 99-102. 